\title{
Factores que intervienen en el éxito deportivo: Una experiencia educativa
}

\author{
Factors involved in football success: an educational experience
}

\author{
Gürkan Diker ${ }^{1}$, Raif Zileli ${ }^{2}$, Hüseyin Özkamçı ${ }^{3}$, Sadi Ön ${ }^{4}$ \\ Sivas Cumhuriyet University, Sivas, Turkey ${ }^{1}$ \\ Bilecik Şeyh Edebali University, Bilecik, Turkey ${ }^{2}$ \\ Dokuz Eylül University, İzmir, Turkey ${ }^{3}$ \\ Ahi Evran University, Kırşehir, Turkey ${ }^{4}$ \\ ORCID ID: https://orcid.org/0000-0003-0407-8238 \\ ORCID ID: https://orcid.org/0000-0003-4178-5468 2 \\ ORCID ID: https://orcid.org/0000-0003-3372-2299 $^{3}$ \\ ORCID ID: https://orcid.org/0000-0002-8047-9861
}

Recibido: 12 de enero de 2021

Aceptado: 01 de diciembre de 2021

\section{Resumen}

El objetivo de este estudio fue evaluar posibles diferencias entre victorias ( 9 partidos) y derrotas (9 partidos) de un equipo de fútbol profesional en una temporada de la Primera Liga Turca del Spor Toto. Durante 18 partidos de las competencias, se analizaron 7 parámetros. Los datos se examinaron en términos de aceleraciones totales (en número), desaceleraciones totales (en número), distancia $(\mathrm{m})$, impacto (en número), distancia de sprint $(\mathrm{m})$ y promedio de velocidad máxima $(\mathrm{km} / \mathrm{h})$. Los datos fueron recopilados utilizando el dispositivo de rastreo GPS Playertek durante los encuentros. La prueba de normalidad de los datos se realizó mediante la prueba de Shapiro-Wilk y la homogeneidad de la variación se evaluó mediante la prueba de homogeneidad de varianza de Levene. Como los datos mostraron una distribución normal en el análisis estadístico, se aplicó la prueba $\mathrm{T}$ de muestras pareadas. La significancia estadística $(\mathrm{p}<0.05)$ fue aceptada en el estudio. Los resultados mostraron que, si bien no hubo una diferencia significativa $(p>0.05)$ en términos de aceleraciones totales (en número), desaceleraciones totales (en número), impacto (en número), distancia de sprint $(\mathrm{m})$ y promedio de velocidad máxima ( $\mathrm{km} / \mathrm{h}$ ) entre las derrotas y las victorias de un equipo de fútbol profesional, en cuanto al parámetro de distancia (m) se encontró diferencia significativa ( $\mathrm{p}<0.05$ ). Teniendo en cuenta esta información, se puede afirmar que la distancia puede ser determinante en los resultados de un partido de fútbol.

Palabras clave: análisis de rendimiento, fútbol, rendimiento en carrera, distancia total, GPS, deportes. 


\begin{abstract}
The aim of this study was to evaluate whether there were any differences between a professional football team's wins (9 matches) and loses (9 matches) in a season in terms of some parameters in Turkish Spor Toto First League. During the total of 18 matches in the competitions, 7 parameters were analysed. The data were analysed in terms of total accelerations (in number), total decelerations (in number), distance (m), impact (in number), sprint distance ( $m$ ) and average of top speed $(\mathrm{km} / \mathrm{h})$. The data were gathered using Playertek GPS tracking device during the matches by the same researcher. As the data showed normal distribution in the statistical analysis, Paired Sample T-Test was applied. The results showed that while there was not a significant difference ( $p>0.05$ ) in terms of total accelerations (in number), total decelerations (in number), impact (in number), sprint distance $(\mathrm{m})$ and average of top speed $(\mathrm{km} / \mathrm{h})$ between the defeats and wins of a professional football team, in terms of distance $(\mathrm{m})$ parameter there found significant difference $(\mathrm{p}<0.05)$. Considering this information, it can be stated that distance can be a determinant in a football game score.
\end{abstract}

Keywords: Performance analysis, soccer, running performance, total distance, GPS, sports.

\title{
Introduction
}

Soccer is one of the most popular sports (Konefal et al., 2021), and the number of people watching it has still been increasing. Therefore, many researchers have been doing research on the field to understand it further in terms of physiological and technical requirements (Rivilla-Garcia et al., 2019; Konefal et al., 2020). Recently, through match analysis, there has been an increase in the existing information on the distance players run (Brandley et al., 2018; Smpokos et al., 2018; Altmann et al., 2021). This is related to the fact that there have been developments in match analysis systems and that coaches are more keen on this subject (Rivilla-Garcia et al., 2019). The literature shows that there are physical demands in the teams which depend on various factors (Rampinini et al., 2007; Harper et al., 2019). Valuable information on a player's performance can be gathered with the help of kinematical analysis during the game. For example, the data on how long a player runs in a match can shed a light to the future training periods or the ways of evaluating the performance of players during the season (Barros et al., 2007).

In this case, Mallo et al., (2015) report that the more intermittent running activities players do, the better variable the distance covered at great intensities when compared with the total distance covered in order to determine the physical requirements of the sport becomes. Professional football players cover about 9-14 $\mathrm{km}$ in a match (Brandley et al., 2013). Bush et al. (2015) state that this is mostly done at low intensity; however, about $7-12 \%$ of this is performed at high intensity 
and only a small portion (1-4\%) of this distance is covered by sprints. Therefore, while coaches are planning the training, they are to take the workload in the first and second half of a match into consideration (Nobari et al., 2021).

There are studies done on parameters such as the running performance of the teams in the same (Nobari et al., 2021; Hoppe et al., 2014) or different leagues (Bradley et al., 2013), the running performance of players in terms of their positions (Hands \& Janse, 2020; Smpokos et al., 2018; Rivilla-Garcia et al., 2018; Andrzejewski et al., 2015; Barros et al., 2007), and the running performance in terms of the ranking in the league (Yang et al., 2018; Rampinini et al., 2007) to investigate the factors affecting the team success. Further parameters can be added to list such as corner kick (Zileli \& Söyler, 2020; Zileli et al., 2017), technique parameters (Göral, 2015), and internal and external workloads (Granero-Gil et al., 2020).

On the other hand, technical and physical indicators that affect the result of the match are not very obvious, and there have been only few studies investigating the effects of these indicators together on the result (Zhou et al., 2018). As there is research done on the factors affecting a football team's success with the international teams, there is a gap to be filled in Turkish National League regarding this subject. Specifically, whether there is a difference between the matches won and lost by a successful football team through the season needs to be determined. As this study sheds a light on the factors affecting the success of a football team, it is very significant. There has not been a study analysing the data gathered on the physical factors during the matches in Turkish Spor Toto First League until now. After this evidence, the aim of this study was to evaluate whether there were any differences between a professional football team's wins (9 matches) and defeats (9 matches) in a season in terms of some parameters in Turkish Spor Toto First League.

\section{Methodology}

\section{The design of the study}

In this study, a total of 18 matches of a professional football team in Turkish Spor Toto First League with 9 wins and 9 defeats in a season were analysed. The matches were randomly selected. The data were analysed in terms of the following parameters: total accelerations (in number), total decelerations (in number), distance (m), impact (in number), sprint distance (m), sprint (in number), top speed average $(\mathrm{km} / \mathrm{h})$. 


\section{Data Collection}

The data collected for the study was gathered by investigating a professional football team's wins (9 matches) and defeats ( 9 matches) in a season in Turkish Spor Toto First League. A total of 18 matches were analysed using Playertek GPS device system (Isère, France) by the same researcher. The study was approved by Bilecik Şeyh Edebali University, University Ethics Committee (202111035).

\section{Statistical analysis}

Normality test of the gathered data was done using Shapiro-Wilk test and variation homogeneity was evaluated using Levene's Test of Homogeneity of Variance. As the data showed normal distribution in the statistical analysis, Paired Sample T-Test was applied. Moreover, means and standard deviation values of the data were obtained. Statistical significance $(\mathrm{p}<0.05)$ was accepted in the study.

\section{Findings}

Below in Table 1 are the findings obtained from the analysis of a professional football team's wins (9 matches) and defeats (9 matches) in a season in Turkish Spor Toto First League.

Table 1

Parameters of the Football Team in the Matches

\begin{tabular}{lllcccc}
\hline \multicolumn{1}{c}{ Parameters } & & $\mathrm{n}$ & $\overline{\mathrm{x}}$ & $\mathrm{sd}$ & $\mathrm{T}$ & $\mathrm{p}$ \\
& & & & & & \\
\hline Total Accelerations (in number) & Win & 9 & 964.67 & 79.03 & 2.04 & 0075 \\
& Defeat & 9 & 863.44 & 105.31 & & \\
Total Decelerations (in number) & Win & 9 & 1110.33 & 102.38 & 0.89 & 0.39 \\
& Defeat & 9 & 1058.89 & 124.50 & & \\
Distance $(\mathrm{km})$ & Win & 9 & 112.41 & 5.55 & 2.91 & $0.019^{*}$ \\
& Defeat & 9 & 105.35 & 5.98 & & \\
Impact (in number) & Win & 9 & 2760.11 & 371.97 & 1.45 & 0.18 \\
& Defeat & 9 & 2425.78 & 375.64 & & \\
Sprint Distance (m) & Win & 9 & 2328.56 & 319.27 & -1.58 & 0.15 \\
Sprint (in number) & Defeat & 9 & 2533.44 & 421.71 & & \\
& Win & 9 & 57.33 & 8.75 & -1.76 & 0.11 \\
& Defeat & 9 & 64.33 & 10.89 & & \\
Top Speed Average $(\mathrm{km} / \mathrm{h})$ & Win & 9 & 29.84 & 0.71 & 0.83 & 0.42 \\
\hline
\end{tabular}


When Table 1 is analysed, it can be seen that there was no statistically significant difference ( $p>0.05)$ in terms of the total accelerations (in number), total decelerations (in number), impact (in number), sprint distance (m), sprint (in number), and top speed average $(\mathrm{km} / \mathrm{h})$. However, in the distance $(\mathrm{m})$ parameter between the professional football team' matches that were won and lost, there found a statistically meaningful difference $(\mathrm{p}<0.05)$.

\section{Discussion}

The aim of this study was to evaluate whether there were any differences between a professional football team's wins ( 9 matches) and defeats ( 9 matches) in a season in terms of total accelerations (in number), total decelerations (in number), distance (m), impact (in number), sprint distance (m), sprint (in number), and top speed average $(\mathrm{km} / \mathrm{h})$ parameters in Turkish Spor Toto First League.

The data collected in the study showed that only the distance $(\mathrm{m})$ parameter showed statistical significance. The other parameters which were the total accelerations (in number), total decelerations (in number), impact (in number), sprint distance (m), sprint (in number), and top speed average $(\mathrm{km} / \mathrm{h})$ were not statistically significant (Table 1). This information indicated once more that for a team to be successful, distance holds an important place.

Similar to the findings of our study, in a research investigating the matches of a football team in the Greek League, it is reported that total distance (10118m; 9488m), maximal sprinting speed running distance $(137 \mathrm{~m} ; 135 \mathrm{~m})$ and very high intensity speed running distance $(482 \mathrm{~m}$; $455 \mathrm{~m}$ ) were found to be higher in the matches that were won compared to the ones lost (Smpokos et al., 2018). In another study, it is stated that successful teams have higher total distance, high intensity running and very high intensity running values than unsuccessful teams (Rampinini et al., 2007). In their study where the link between the match status (wining, losing) and physical activities of a football team was investigated, Moalla et al. (2018) found that when a team won, longer total distance covered by the players and low-intensity running $(<14.4 \mathrm{kmh}-1)$ were distinguishing factors; however, the players sprinted more $(\geq 25.2 \mathrm{kmh}-1)$ and ran with higherintensity $(\geq 19.8 \mathrm{kmh}-1)$ when they lost. In another study, it is stated that successful teams have higher workloads in win matches when compared with draw or defeat for all variables (total distance, high-speed running distance, total sprint distance, average speed, maximal speed) (Nobari 
et al., 2021). In a research investigating the matches of a football team in the Spanish League total distance $(>21 \mathrm{kmh}-1)$ without ball possession increased when teams were winning, and decreased when teams were losing (Ponce-Bordón et al., 2021). Similar findings were also found in this study.

There are also studies not corresponding with our findings. In Italy-Serie A League, the top five and bottom five teams were compared. The distance covered by the top five teams was discovered to be less than the total distance covered by the bottom five teams which were respectively $11647 \mathrm{~m}$ and $12190 \mathrm{~m}$. However, the statistically significant parameters of successful teams were total distance with the ball $(540 \mathrm{~m}, 443 \mathrm{~m})$, high-intensity running with the ball $(299 \mathrm{~m}$, $251 \mathrm{~m})$, and very high-intensity running with the ball $(127 \mathrm{~m}, 109 \mathrm{~m})$, which all highly benefitted the team (Rampinini et al., 2009). In addition, the total distance covered by the top four teams in Chinese Super League competitions in 2014 was found to be lower than the distance covered by the bottom four teams (respectively 108009m and 109116m). Nevertheless, the parameters: total sprint (2183m, 2052m), total high intensity (4810m, 4594m), and total high speed (2643m, 2530m) were emphasized to be statistically significant and benefitting the successful teams (Yang et al., 2018).

In another study in which the physical performance parameters of the English Premier League, English Championship and English First League were compared, it was observed that the teams in the First League ran shorter distance than the ones in Premier League and the Championship and that the teams in the Championship covered greater distance than the ones in the Premier League (respectively 10722m, 11429m, and 11608m). The league with the shortest distance covered between these three was English Premier League which also had the highest level (Bradley et al., 2013).

In 2014 FIFA World Cup, it was discovered that the physical performance parameters (distance, low, middle and high intensity running) of winning and defeated teams were similar, and there was not a statistically significant difference (Rumpf et al., 2017). In a study where the teams that won and defeated the 2018 World Cup were analysed, there was no significant difference between the two groups (Gürkan et al., 2019). In another study done in Spanish League, the First and Second Division League teams covered similar distances, but the former covered greater distance at high intensity and very high intensity (Gomez-Piqueras et al., 2019). It can also definitely be said that running performance during the matches does not single-handedly determine 
the success of German Bundesliga teams. On the contrary, the combination of it with technical/tactical skills in terms of possessing the ball is very significant (Hoppe et al., 2015). In another study, it is stated that differences in tournaments and match periods were found in almost all variables (based on Principal Component Analysis (PCA), finding the highest external workload in draw matches when match outcome was considered a factor (Rojas-Valverde et al., 2007).

The findings of our study show similarities and differences with the literature. In this study, distance was found to be a statistically significant parameter. However, this alone may not be an adequate parameter considering the results of the studies in the literature. When means of each parameter were analysed, in the matches that were won, total accelerations (respectively 964.67, 863.44 times), total decelerations (1110.33, 1058.89 times) and impact (2760.11, 2425.78 times) were found to be high; sprint distance $(2328.56,2533.44 \mathrm{~m})$ and sprint $(57.33,64.33$ times) were found to be low; top speed $(29.84,29.55 \mathrm{~km} / \mathrm{h})$ was found to be equal with the matches that were lost.

A number of limitations could be recognized with a view to future research. For example, other context-related variables such as ball possession percentage and player position were not considered. Another limitation of our study was that physical levels of opposing teams could not be included. Another of the main limitations of this study is not knowing the players' previous and subsequent fatigue levels in each of the matches.

\section{Conclusion}

Therefore, it is noteworthy that different parameters can also be important rather than a single one. In this regard, many factors such as technical, tactical and environmental factors can affect the result of the competition. The limitations of this study were the fact that technical and tactical factors and the physical performance of the opposing team were not looked into. In this context, the most significant result of the study is that distance is an important outcome of physical performance. It is suggested that coaches concentrate highly on endurance exercises to increase the distance that can be covered. 


\section{References}

Altmann, S., Forcher, L., Ruf, L., Beavan, A. \& Groß, T. (2021). Match-related physical performance in professional soccer: Position or player specific?. PLOS ONE 16 (9): e0256695. https://doi.org/10.1371/journal.pone.0256695

Andrzejewski, M., Chmura, J., Pluta, B. \& Konarski, J. M. (2015). Sprinting activities and distance covered by top level Europe League soccer players. International Journal of Sports Science \& Coaching. 10 (1): 39-50. https://doi.org/10.1260/1747-9541.10.1.39

Barros, R. M., Misuta, M. S., Menezes, R. P., Figueroa, P. J., Moura, F. A., Cunha, S. A., Anido, R., \& Leite, N. J. (2007). Analysis of the distances covered by first division Brazilian soccer players obtained with an automatic tracking method. Journal of sports science \& medicine, 6 (2), 233-242. https://www.ncbi.nlm.nih.gov/pmc/articles/PMC3786245/

Bourdon, P. C., Cardinale, M., Murray, A., Gastin, P., Kellmann, M., Varley, M. C., Gabbett, T. J., Coutts, A. J., Burgess, D. J. \& Gregson, W. (2017). Monitoring athlete training loads: Consensus statement. Int. J. Sports Physiol. Perform., 12, S2161-S2170. https://doi.org/10.1123/IJSPP.2017-0208

Bradley, P. S., Carling, C., Gomez Diaz, A., Hood, P., Barnes, C., Ade, J., Boddy, M., Krustrup, P., Mohr, M. (2013) Match performance and physical capacity of players in the top three competitive standards of English professional soccer. Hum Mov Sci. 32 (4):808-21. doi: 10.1016/j.humov.2013.06.002. Epub 2013 Aug 24. PMID: 23978417.

Bradley, P. S. \& Ade, J. D. (2018). Are Current Physical Match Performance Metrics in Elite Soccer Fit for Purpose or Is the Adoption of an Integrated Approach Needed? Int. J. Sports Physiol. Perform., 13, 656-664. https://doi.org/10.1123/ijspp.2017-0433

Bradley, P. S., Carling, C., Archer, D., Roberts, J., Dodds, A., Di Mascio, M., Paul, D., Diaz, A. G., Peart, D., Krustrup, P. (2011). The effect of playing formation on high-intensity running and technical profiles in English FA Premier League soccer matches. J. Sports Sci., 29, 821830. https://doi.org/10.1080/02640414.2011.561868 
Bush, M., Barnes, C., Archer, D. T., Hogg, B., \& Bradley, P. S. (2015). Evolution of match performance parameters for various playing positions in the English Premier League. Human Movement Science, 39, 1-11. http://doi.org/10.1016/j.humov.2014.10.003

Gomez-Piqueras, P., Gonzalez-Villora, S., Castellano, J., \& Teoldo, I. (2019). Relation between the physical demands and success in professional soccer players. Journal of Human Sport and Exercise, 14 (1), 1-11. doi: https://doi.org/10.14198/jhse.2019.141.01

Granero-Gil, P., Bastida-Castillo, A., Rojas-Valverde, D., Gómez-Carmona, C. D., De la Cruz Sánchez, E. \& Pino-Ortega, J. (2020). Influence of Contextual Variables in the Changes of Direction and Centripetal Force Generated during an Elite-Level Soccer Team Season. Int. J. Environ. Res. Public Health, 17, 967. doi:10.3390/ijerph17030967

Gürkan, O., Cihan, B.B., Yıldırım, M. \& Gümüşdağ, H. (2019). Comparing the Some Performance Parameters of the Winning and Losing Teams of World Cup 2018. Gaziantep University Journal of Sport Science, 4 (4), 426-436. doi.org/10.31680/gaunjss.567109

Hands, D.E., Janse de Jonge, X. (2020). Current time-motion analyses of professional football matches in top-level domestic leagues: a systematic review. International Journal of Performance Analysis in Sport. 20: 747-65. ttps://doi.org/10.1080/24748668.2020.1780872

Harper, D. J., Carling, C. \& Kiely, J. (2019). High-Intensity Acceleration and Deceleration Demands in Elite Team Sports Competitive Match Play: A Systematic Review and MetaAnalysis of Observational Studies. Sports Med. 49, 1923-1947. doi.org/10.1007/s40279019-01170-1

Hoppe, M. W., Slomka, M., Baumgart, C., Weber, H., Freiwald, J. (2015). Match running performance and success across a season in German Bundesliga soccer teams. Int J Sports Med. 36 (7),563-566. doi: 10.1055/s-0034-1398578

Konefał, M., Andrzejewski, M., Chmura, P., Zacharko, M. \& Radziminski, Ł. (2021). Physical Activity of the Right- and Left-Footed Professional Soccer Players from Symmetrical Defensive Positions. Symmetry, 13, 1551. doi.org/10.3390/sym13091551

Konefał, M., Chmura, P., Tessitore, A., Melcer, T., Kowalczuk, E., Chmura, J. \& Andrzejewski, M. (2020). The Impact of Match Location and Players' Physical and Technical Activities on 
Winning in the German Bundesliga. Front. Psychol. 11, 1748. doi.org/10.3389/fpsyg.2020.01748

Mallo, J., Mena, E., Nevado, F. \& Paredes, V. (2015) Physical Demands of Top-Class Soccer Friendly Matches in Relation to a Playing Position Using Global Positioning System $\begin{array}{llllll}\text { Technology. } & J & \text { Hum } & \text { Kinet, } & 47 & \text { (1): }\end{array}$ https://www.ncbi.nlm.nih.gov/pmc/articles/PMC4633253/

Moalla, W., Fessi, M. S., Makni, E., Dellal, A., Filetti, C., Di Salvo, V. \& Chamari, K. (2018). Association of Physical and Technical Activities with Partial Match Status in a Soccer Professional Team. J Strength Cond Res, 32 (6):1708-1714. doi: 10.1519/JSC.0000000000002033. PMID: 29786627.

Nobari, H., Oliveira, R., Brito, J. P., Pérez-Gómez, J., Clemente, F. M. \& Ardigò, L. P. (2021). Comparison of Running Distance Variables and Body Load in Competitions Based on Their Results: A Full-Season Study of Professional Soccer Players. Int. J. Environ. Res. Public Health, 18, 2077. https://doi.org/10.3390/ ijerph18042077.

Ponce-Bordón, J.C., Díaz-García, J., López-Gajardo, M.A., Lobo-Triviño, D., López del Campo, R., Resta, R. \& García-Calvo, T. (2021). The Influence of Time Winning and Time Losing on Position-Specific Match Physical Demands in the Top One Spanish Soccer League. Sensors. 21, 6843. https://doi.org/10.3390/ s21206843

Rampinini, E., Coutts, A. J., Castagna, C., Sassi, R., Impellizzeri, F.M. (2007) Variation in top level soccer match performance. Int J Sports Med. 28 (12): 1018-24. doi: 10.1055/s-2007965158. Epub May 11. PMID: 17497575.

Rampinini, E., Impellizzeri, F. M., Castagna, C., Coutts, A. J. \& Wisløff, U. (2009) Technical performance during soccer matches of the Italian Serie A league: effect of fatigue and competitive level. J Sci Med Sport. 12 (1):227-33. doi: 10.1016/j.jsams.2007.10.002. Epub 2008 Feb 20. PMID: 18083631.

Rivilla-García, J., Calvo, L. C., Jiménez-Rubio, S., Paredes-Hernández, V., Muñoz, A., van den Tillaar, R., \& Navandar, A. (2019). Characteristics of very high intensity runs of soccer 
players in relation to their playing position and playing half in the 2013-14 spanish La Liga Season. Journal of human kinetics, 66, 213-222. https://doi.org/10.2478/hukin-2018-0058

Rojas-Valverde, D., Gómez-Carmona, C.D., Castillo, A.B., Nakamura F.Y., Giménez-Martínez, E., Matabosch-Pijuán M., Bernal J.R. \& Pino-Ortega J. (2021). A longitudinal analysis and data mining of the most representative external workload indicators of the whole elite Mexican soccer clubs elite Mexican soccer clubs, International Journal of Performance Analysis in Sport, doi: 10.1080/24748668.2021.1996131

Rumpf, M. C., Silva, J. R., Hertzog, M., Farooq, A. \& Nassis, G. (2017). Technical and physical analysis of the 2014 FIFA World Cup Brazil: winners vs. losers. J Sports Med Phys Fitness. 57 (10): 1338-1343. doi: 10.23736/S0022-4707.16.06440-9. Epub 2016 May 11. PMID: 27167712.

Smpokos, E., Mourikis, C., \& Linardakis, M. (2018). Seasonal physical performance of a professional team's football players in a national league and European matches. Journal of Human Sport and Exercise, 13 (4), 720-730. doi:https://doi.org/10.14198/jhse.2018.134.01

Yang, G., Leicht, A. S., Lago, C. \& Gómez, M. A. (2018) Key team physical and technical performance indicators indicative of team quality in the soccer Chinese super league. Res Sports Med. 26 (2):158-167. doi: 10.1080/15438627.2018.1431539. Epub 2018 Jan 31. PMID: 29382229.

Zhou, C., Zhang, S., Calvo, A. L. \& Cui, Y. (2018) Chinese soccer association super league, 20122017: key performance indicators in balance games, International Journal of Performance Analysis in Sport, 18 (4), 645-656, doi: 10.1080/24748668.2018.1509254

Zileli, R., Söyler, M. \& Genç, A. (2017) 2016-2017 Match Analysis of Corner Kicks used in the Turkcell Super League. Inonu University, Journal of Physical Education and Sport Sciences, 4 (3), 48-58 https://dergipark.org.tr/tr/pub/inubesyo/issue/33673/349143

Zileli, R., \& Söyler, M. (2020). Analysis of corner kicks in FIFA 2018 World Cup. Journal of Human Sport and Exercise. doi:https://doi.org/10.14198/jhse.2022.171.15 